Implicit Gender Bias, Engagement, and Protective Factors in STEM Faculty 


\begin{abstract}
The present study assessed implicit gender bias and job engagement among STEM faculty at a mid-size liberal arts university. Forty-nine faculty in each of the departments of natural and social sciences were assessed for implicit gender bias and job engagement. We found that men had greater implicit gender bias than women in the natural sciences. In addition, women in natural science departments felt marginally less engaged than women in social science departments. Women's disengagement was positively associated with imposter phenomenon and perceived lack of control in departmental decisions. However, women who actively participated in a women's organization or had an advocate had more positive psychological outcomes. These findings suggest that although women STEM faculty, particularly in the natural sciences, experience challenges, support provided by women's organizations or advocates may be an important strategy to reduce the effects of these challenges.
\end{abstract}




\section{Implicit Gender Bias, Engagement, and Protective Factors in STEM Faculty}

Gender differences in academia have been well-documented for decades. According to the literature, in North America and Europe, women have traditionally been overrepresented in lower ranking positions, taught heavier course loads, received less research support, served on more committees, and played less prominent roles in decision-making compared to men (e.g., August \& Waltman 2004; Gander, 1999; Glazer-Raymo, 1999; House of Commons Science and Technology Committee, 2014; O’Dorchai, Meulders, Crippa, \& Margherita, 2009; Park, 1996). This phenomenon has been particularly prevalent in the science, technology, engineering, and mathematics (STEM) disciplines. Understanding the factors that contribute to gender differences remains a primary focus for faculty, staff, and administrators, who seek to increase gender inclusion within the academy generally and STEM field in particular. The current study sought to assess implicit gender bias and job engagement among STEM faculty, and to investigate potential protective factors for women STEM faculty.

Gender Stereotypes in the Academy

Over the past two decades, a wide array of factors have been identified that contribute to gender differences in STEM, which include the structure of the academy (Husu, 2005; Niemeier \& Gonzalez, 2004; Sonnert \& Holton, 1996; White, 2015), workplace and campus climate (Liang \& Bilimoria, 2007; Rosser, 2004), a lack of family-friendly policies (Shollen, Bland, Finstad, \& Taylor, 2009), and women's career choices (Ceci \& Williams, 2011; Ceci, Williams, $\&$ Barnett, 2009). One additional salient factor is the presence of cultural stereotypes about women in the natural sciences (e.g., Heilman, 2001). Despite research that indicates that men are no more capable in science and math than women (e.g., Spelke, 2005), the stereotype that 
women's scientific abilities are inferior to that of men has been prominent in STEM fields (Cheryan, Plaut, Davies, \& Steele, 2009; Diekman, Brown, Johnston, \& Clark, 2010).

Although people may not explicitly endorse gender stereotypes because of salient societal norms (Schmader, Johns, \& Barquissau, 2004), they may nonetheless hold negative implicit associations between women and science without their awareness. For example, research has demonstrated that most men and women, including those who strive to be egalitarian (Dovidio \& Gaertner, 2004), more readily implicitly associate men with science fields and women with humanities and social sciences (Nosek et al., 2009). Implicit biases lead to negative evaluations of stereotyped group members (Blair, 2001) as well as discomfort with, and negative behavior toward, stereotyped individuals (e.g., Dovidio, Kawakami, \& Gaertner, 2002; Fazio, Jackson, Dunton, \& Williams, 1995). This has traditionally resulted in significantly fewer girls pursuing STEM disciplines, leading to proportionally fewer women who are qualified for faculty positions than men in these fields (National Science Board, 2012). As a result, many of these fields are male-dominated (National Science Foundation, 2004). Because sexist attitudes are stronger and more prevalent in areas of expertise that are traditionally male-dominated (Sonnert \& Holton, 1996), sexual harassment and gender discrimination are more frequently reported in natural science departments than in social science departments (e.g., Hesson-McInnis \& Fitzgerald, 1997; Settles, Cortina, Malley, \& Stewart, 2006).

More recently, the gender composition of STEM departments has started to shift. A recent National Research Council (NRC; 2009) analysis revealed that, relative to men, women were hired at higher rates in every field assessed, including STEM fields. This finding was supported by Ceci and Williams (2015), who demonstrated that STEM departments are now hiring women over men, as long as they are equally-qualified. However, despite this change in 
hiring trends in STEM fields, environmental and psychological factors continue to impact women faculty's job engagement. Job engagement reflects fulfillment with tasks at work (Schaufeli, Salanova, Gonzalez-Roma, \& Bakker, 2002), including involvement with, and enthusiasm for, one's job as well as intention to stay with an employer (Harter, Schmidt, \& Hayes, 2002; Macey \& Schneider, 2008).

According to Self-Determination Theory (Deci \& Ryan, 1985; Deci \& Vansteenkiste, 2004; Ryan \& Deci, 2000) creativity, motivation, and performance, key components of a faculty member's job engagement, increase when individuals satisfy the following three needs: opportunities for learning and mastery (competency), flexibility and control over processes and outcomes (autonomy), and the formation of meaningful connections with others (relatedness). A goal of the current study was to examine whether implicit gender bias and job engagement are associated with psychological and environmental factors that reflect feelings of competency, autonomy, and relatedness in faculty members in STEM departments.

\section{Women's Feelings of Competency in STEM}

Like men, women may endorse explicit gender stereotypes (Blanton, Christie, \& Dye, 2002) and hold implicit biases about women in science (Nosek, Banaji, \& Greenwald, 2002). For those in STEM fields, these explicit and implicit biases can have negative effects on performance (Nosek et al., 2002) and interest in the field (Schmader et al., 2004). Women who endorse gender stereotypes are more susceptible to stereotype threat (Schmader et al., 2004), which is a phenomenon in which a group member worries about confirming negative stereotypes about their group. Women and girls in STEM fields may try to avoid confirming negative stereotypes 
about women in science, which can lead to underperformance and disengagement (Kiefer \& Sekaquaptewa, 2007; Nosek et al., 2002; Schmader et al., 2004; Steele, 1997).

Another phenomenon commonly observed in women in STEM who endorse biases is the impostor phenomenon, which reflects emotional and cognitive anxiety related to taking credit for their success. When successful, those who feel like imposters are less likely to make internal attributions to their ability (Topping \& Kimmel, 1985) and more likely to make external attributions to luck or effort (Chae, Piedmont, Estadt, \& Wicks, 1995; Clance, 1985; Thompson, Davis, \& Davidson, 1998). High-achieving women who are minorities in their profession, such as women in STEM fields, experience imposter phenomenon more so than men, even if their actual performance is objectively the same as men (e.g., King \& Cooley, 1995; Kumar \& Jagacinski, 2006; Legassie, Zibrowksi, \& Goldszmidt, 2008; but see Fried-Buchalter, 1997; Topping \& Kimmel, 1985).

Imposter phenomenon can contribute to feelings of stress or anxiety (Clance \& Imes, 1978); this stress can in turn lead to disengagement with work, decreased productivity, and lower job satisfaction (Li, Early, Mahrer, Klaristeenfeld, \& Gold, 2014; Hagedorn, 2000), and ultimately lead to the decision to leave academia (Barnes, Agago, \& Coombs, 1998). Women faculty experience more job stress than male faculty (Hurtado, Eagan, Pryor, Whang, \& Tran, 2012) and this stress may be compounded by working in a male-dominated career (e.g., Williams, Fitzgerald, \& Drasgow, 1999). Another source of stress for women may be subtle discrimination; indeed, women faculty are twice as likely as male faculty to experience stress as a result of implicit discrimination (Hurtado et al., 2012). Given the relationship between stress and disengagement, women STEM faculty may be less engaged with their jobs than men, as well as their non-STEM counterparts. 
Women's Feelings of Autonomy in STEM

Interaction with colleagues who have implicit gender biases can lead women faculty in STEM disciplines to perceive a negative departmental climate (Schneider, Ehrhart, \& Macey, 2013). Departmental climate, defined as one's evaluation of interrelated experiences in the workplace, affects job satisfaction and intentions to quit (Callister, 2006). As discussed by Maranto and Griffin (2011), a "chilly" departmental climate that excludes, devalues, and/or marginalizes women can serve as a barrier to achievement and advancement (e.g., Preston, 2004). One way that this likely occurs is by decreasing women's autonomy by excluding them from departmental decisions (Schneider, 1975). Having less input in a workplace is associated with decreased agency, lower self-confidence, and underachievement (Fine \& Weis, 2003; Jack, 1991; Settles, Cortina, Stewart, \& Malley, 2007), all of which can predict job engagement (Colquitt, Conlon, Wesson, Porter, \& Ng, 2001).

In academia, the exclusion of women from decision-making is a common issue (e.g., Hopkins, Bailyn, Gibson, \& Hammonds, 2002) and women faculty tend to feel that they play less of a role in decision-making at their institution than their male colleagues, even after controlling for academic rank, years after completion of the Ph.D., and years of teaching experience (Denton \& Zeytinoglu, 1993). Women in natural science departments often report perceptions that they have less influence and fewer leadership opportunities than men in their institutions (e.g., Niemeier \& Gonzalez, 2004) and feel more isolated compared to those in social science departments (Liang \& Bilimoria, 2007; Rosser, 2004). In a report released by the Massachusetts Institute of Technology (1999), women's exclusion from $\mathrm{PhD}$ committees, group grants, and decision-making was a common problem across departments. Examining these issues 
is important, as a negative perception of department climate is the most common reason why women choose to leave their position in the academy. This reason is more salient than salary, the top reason why men report a desire to leave their positions (Callister, 2006).

\section{Women's Feelings of Relatedness in STEM}

The environmental factors (i.e., departmental climate) and psychological factors (i.e., stereotype endorsement, imposter phenomenon, and stress) discussed above may be mitigated by protective factors. For example, feelings of belonging predict persistence in STEM for women faculty (e.g., Good, Rattan, \& Dweck, 2012). This is especially true when there are gender differences, particularly in leadership positions, in their field or department (Cheryan et al., 2009; Murphy, Steele, \& Gross, 2007).

Increasing feelings of belonging could have positive impacts on women's productivity and satisfaction. One way to increase feelings of belonging is to have a mentor, which has been shown to promote feelings of support and belonging that lead women faculty to stay at their institution (Chesler \& Chesler, 2002; Stockard, Greene, Lewis, \& Richmond, 2010). According to Feldman, Arean, Marshall, Lovett, and O’Sullivan (2010), women who have a mentor experience greater satisfaction at work and higher academic self-efficacy. Although many women faculty have a mentor, fewer may have an advocate; i.e., someone who speaks or writes in support or defense of a faculty member. As women have less access than men to social and professional networks (Bagilhole \& White, 2013), they are at a disadvantage socially and professionally (Milem, Sherlin, \& Irwin, 2001; Sagebiel, 2005). Therefore, advocates may help women faculty gain access to these networks, which may increase feelings of belonging and facilitate career advancement (Bagilhole \& White, 2013). 
Likewise, being connected to professional networks increases access to crucial information about the field, offers more opportunities for advancement, and provides more interpersonal support (Sonnert \& Holten, 1996). Professional networks can also be established through participation in an organization to support women faculty and can increase women faculty's sense of belonging in the field (Kemelgor \& Etzkowitz, 2001), particularly because women's relational support has positive implications for climate and job satisfaction (Billmoria, Perry, Liang, Stoller, Higgins, \& Taylor, 2006). More research examining these potential protective factors is needed. Whether having an advocate or participating in a women's organization is associated with more positive psychological outcomes should be examined.

\section{Goals and Hypotheses of the Current Study}

In the present study, implicit bias was assessed in faculty from natural science and social science departments using the Gender-Science Implicit Association Test (IAT; Nosek et al., 2002), which measures implicit associations that individuals have between gender and the sciences. We hypothesized that there would be implicit bias against women in STEM fields. We also measured the degree to which STEM faculty feel engaged with their position by assessing enthusiasm, pride, positive affect, and engrossment in work. For engagement, we sought to examine whether responses would vary as a function of gender and discipline (natural vs. social sciences). We hypothesized that women in natural science departments would feel less engaged than those in social science departments, as previous research demonstrates that women in natural science departments tend to feel more isolated (Liang \& Bilimoria, 2007; Rosser, 2004). In addition, women in natural science departments may experience more stress than women in social science departments, as greater stress is seen in women working in a male-dominated area 
compared to a more gender-balanced field (e.g., Williams, Fitzgerald, \& Drasgow, 1999). We also predicted that male faculty would not differ between the fields.

In addition, we looked at several environmental and psychological variables that could be associated with implicit bias and engagement in STEM women faculty using Self-Determination Theory as a theoretical framework. Specifically, we investigated factors associated with competence, autonomy, and belongingness, as outlined below. With respect to competence, we examined stereotype endorsement, imposter phenomenon, and stress, to determine whether implicit bias and engagement differed as a function of the gender stereotypes that women hold about their group. We predicted that implicit bias and job engagement would be associated with these factors.

Autonomy was assessed by measuring the degree to which women felt that they played a role in the decision making in their institution. Other research has shown that women faculty tend to feel that they play less of a role in decision-making at their institution than men (Denton \& Zeytinoglu, 1993), particularly in natural science departments (MIT, 1999) which can affect autonomy and persistence (Callister, 2006). Therefore, we hypothesized that greater implicit bias and greater disengagement for the STEM women faculty in our study would be associated with perceptions that they did not play a meaningful role in the department decision-making process.

Finally, we assessed whether support through means such as having an advocate or involvement in a women's organization played a protective role. We hypothesized that the presence of an advocate or involvement in a women's organization would be associated with more positive outcomes, such as less implicit bias, more engagement, feeling less disparity in the decision-making of their department, experiencing less imposter phenomenon, feeling less stress, 
and endorsing fewer gender stereotypes. This study was conducted at an R2 institution to extend the results of previous work that has mostly focused on large, tier one (R1) research universities.

\section{Method}

\section{Participants}

One hundred thirty-eight (78 women and 60 men) full-time faculty at a medium-sized mid-Atlantic elite state university completed this study. Of the 138 faculty who completed the study, nine failed to indicate their discipline and were excluded from the analyses below, as were faculty who were members of a humanities department $(n=21)$, the business school $(n=5)$, and the law school $(n=5)$. Faculty who were members of fields that are eligible to receive funding from NSF (i.e., the natural science fields of Biology; Computer Science; Environmental Sciences; Geology; Mathematics; Physics; Applied Science; Neuroscience as well as the social science fields of Education and Social, Behavioral, and Economic Science) were included in the analyses below. The final sample of 98 faculty included 49 social science faculty and 49 natural science faculty. The faculty members consisted of 31 assistant professors, 32 associate professors and 35 full professors. Of these individuals, $91.8 \%$ were White, $1.0 \%$ were Black, $3.1 \%$ were Asian, 2.1\% were multiracial, and 2.0\% did not indicate their race.

This study was conducted at a university that has been classified as a Tier 2 (R2) research university according to the Carnegie Classification of Institutions of Higher Education. There is a strong focus at this institution for successful integration of teaching and research with undergraduate students who are immersed in a liberal arts and science curriculum. In terms of this institution's history with gender and STEM, it is quite similar to other institutions in the US. Although women have traditionally been a minority in STEM disciplines, similar to other institutions today, the percentage of women in STEM is growing. 
The study was advertised through email, and participants completed the study on their own time. Participants who completed the study were entered into a drawing to receive one of several gift cards. All procedures were approved by the University's Protection of Human Subjects Committee, and an online informed consent was obtained from each participant.

\section{Materials}

Implicit Bias Measure. Participants completed the Gender-Science IAT (Nosek et al., 2002), which assesses the degree to which respondents implicitly associate science and liberal arts terms with male and female terms. Because the version of the software for online data collection required a Windows Personal Computer, some participants could not complete this part of the study because they had a Macintosh computer. Additionally, some participants may have had difficulty with, or not been willing to install, the software necessary to complete the study. Therefore, a subset of 44 (26 women) participants completed this measure. The IAT is a reaction time task in which participants categorize words into superordinate categories in several different blocks. In one block, participants categorize male items (i.e., male, man, boy, brother, him, his, son) and science items (i.e., astronomy, chemistry, physics, biology, biophysics, engineering, biochemistry, neuroscience) with one response key, and female items (i.e., female, woman, girl, sister, she, her, hers, daughter) and liberal arts items (i.e., philosophy, arts, humanities, history, Spanish, English, Latin, music) using another response key. In a subsequent block, these response keys are switched such that female items have the same response key as science items, and male items have the same response key as liberal arts items. The order in which these blocks are presented was counterbalanced across participants in the current study. The difference in reaction time between pairing male and science compared to female and science was calculated and interpreted as an implicit gender-science association. That is, faster 
reaction times to categorize science words with the male category than the female category suggested a bias towards men and science relative to women and science. The exact timing and procedure of the IAT are described further in Nosek et al. (2002).

Questionnaires. In addition to indicating their academic rank (i.e., assistant, associate, or full professor) and providing demographic information such as gender and race, participants also completed several questionnaires that assessed the degree to which they were engaged with their jobs, as well as psychological variables that were related to feelings of competence, autonomy, and belonging (as explained above).

Engagement. Engagement was assessed with the Utrecht Work Engagement Scale (UWES; Schaufeli, Bakker, \& Salanova, 2006). The UWES assesses enthusiasm, pride, positive affect, and engrossment in work and has been used in the organizational behavior literature to study engagement in a variety of professions, including higher education (e.g., Bezuidenhout \& Cilliers, 2010; Mudrak, Zabrodska, Kveton, Jelinek, Blatny, Solcova, \& Machovcova, 2018; Van den Berg, Bakker, \& Ten Cate, 2013). The items of the UWES are scored on a 7-point frequency rating scale ranging from 1 (never) to 7 (always). Sample items include "I find the work that I do full of meaning and purpose"; "I am enthusiastic about my job"; and "When I get up in the morning, I feel like going to work."

Competency. In order to assess perceptions of competency we measured explicit attitudes toward women in science, imposter phenomenon and participants' perceived stress.

The Gender Stereotyping Endorsement Scale (Schmader et al., 2004; $\alpha=.88$ ) was used to measure explicit attitudes. This scale has been used to assess the effects that stereotype endorsement has on women's perceptions of themselves, their career intentions, and their susceptibility to stereotype threat in STEM disciplines (Schmader et al., 2004). It has been used 
to understand how perceptions of women in STEM affect women's academic and career choices in STEM fields (e.g., Lent, Sheu, Miller, Cusick, Penn, \& Truong, 2018; Riegle-Crumb \& Morton, 2017). This scale is made up of three items that specifically relate to women's performance in math and science disciplines. Participants rate the extent to which they agree with questions such as "In general, men may be better than women in math" on a 7-point scale from 1 (strongly disagree) to 7 (strongly agree).

To examine the degree to which faculty felt imposter phenomenon, they completed the Imposter Phenomenon Scale (Clance, 1985; $\alpha=.96$ ), which assesses the degree to which participants think that even though they are often very successful by external standards, they feel their success has been due to luck or great effort. Previous research has utilized this scale to examine imposter phenomenon as a psychological barrier that women in STEM face (e.g., Howe-Walsh \& Turnbull, 2016). The items are scored on a 5-point frequency rating scale ranging from 1 (not at all true) to 5 (very true). An example of an item on the scale is "Sometimes I'm afraid others will discover how much knowledge or ability I really lack." We also asked participants to indicate their stress level on a scale of 1-100.

Autonomy. To assess perceptions of autonomy, we measured department decisionmaking by asking "Who do you feel is responsible for making decisions in your department?" Responses were made using a slide bar with 101 points that ranged from $0=$ males only, $50=$ males and females equally, 100=females only. This was adapted from Settles et al. (2007), who found that the relationship between perceptions of department climate and job satisfaction was weaker for STEM women faculty who felt that they had more of a voice in departmental decisions. Subsequent research has used this item to examine the relationship between women's perceptions of climate and job engagement within academia and women's contributions to 
departmental decision-making (e.g., Holleran, Whitehead, Schmade, \& Mehl, 2011; Maranto \& Griffin, 2011).

Relatedness and Belonging. We assessed relatedness and belonging by asking participants to indicate if they felt that they had an advocate, which was defined for them as "a person who speaks or writes in support or defense of a person.” In addition, participants were asked if they currently belong to a women's organization that serves women faculty members or women scientists.

\section{Procedure}

Potential participants were emailed a link to the study, where they read an informed consent form and indicated their understanding and agreement of consent. The IAT was administered using Inquisit software (www.millisecond.com) and the online questionnaires used Qualtrics software (www.qualtrics.com). These sections were matched by a unique identification number that was provided by each participant. Following the completion of the study, participants were given a debriefing statement and the name and contact information of the researcher responsible for the study.

\section{Data Analyses}

In order to examine the effect of gender and discipline on implicit bias and engagement, two 2 (Gender: Male, Female) x 2 (Discipline: Social Science, Natural Science) betweensubjects analyses of variance (ANOVA) were conducted with each dependent variable of interest. In addition, a multiple regression analysis for women faculty was performed predicting IAT score and engagement from departmental decision-making, imposter phenomenon, stress, and stereotype endorsement. Finally, we investigated whether having an advocate and belonging 
to a women's organization would be associated with positive outcomes on the above variables by using independent samples t-tests.

\section{Results}

\section{Implicit Bias}

The IAT d score was calculated as recommended by Greenwald, Nosek, and Banaji (2003). Trials with reaction times (RTs) greater than 10,000 ms were deleted, and participants for whom more than $10 \%$ of trials had RTs shorter than 300 ms were not used. Higher d scores indicated a stronger association between stereotype congruent categories (e.g., math-males; humanities-females) than stereotype incongruent categories (e.g., math-females; humanitiesmales). The IAT scores ranged from -0.78 to 1.31 , with an average score of $0.41(S D=0.52)$, which is similar to the national average (Nosek et al., 2009). The d score was significantly different from 0 , indicating an overall bias more strongly associating males with math and females with humanities, $t(43)=5.25, p<.001$.

An ANOVA was conducted with IAT d score as the dependent variable. As shown in Figure 1, results revealed the predicted Gender x Discipline interaction, $F(1,40)=7.34, p=$ $.010, \eta^{2}=.155$. For natural science faculty, there was a significant gender difference that emerged such that men $(M=0.57, S E=0.15)$ had more biased attitudes than women $(M=0.09$, $S E=0.13), F(1,20)=5.86, p=.025, \eta^{2}=.227$. For the social science faculty, men $(M=0.35$, $S E=0.17)$ had similar attitudes to women $(M=0.66, S E=0.14), F(1,20)=2.13, p=.160, \eta^{2}=$ .096.

\section{Engagement}

With respect to faculty engagement there was a significant main effect of gender, such that women felt more engaged than men, $F(1,48)=4.94, p=.031, \eta^{2}=.093$. As depicted in 
Figure 2, there was also a marginally significant interaction, $F(1,48)=3.49, p=.068, \eta^{2}=.068$. Simple main effects revealed that women in the natural sciences $(M=6.19, S E=.26)$ felt marginally less engaged than women in the social sciences $(M=6.19, \mathrm{SE}=.24), F(1,24)=3.18$, $p=.087, \eta^{2}=.117$. There were no such discipline-related differences for men, $F(1,24)=0.99, p$ $=.330, \eta^{2}=.040$.

\section{Predictors of Women Faculty's Gender Bias and Engagement}

Next, we examined how implicit bias is related to the variables measured to reflect competence and autonomy in female faculty. To examine these relationships, a regression analysis was performed predicting IAT scores from stereotype endorsement $(M=2.54, S D=$ $1.47)$, imposter phenomenon $(M=2.60, S D=0.64)$, stress $(M=61.08, S D=22.70)$, and department decision-making $(M=43.79, S D=16.94)$. As demonstrated in Table 1, overall stress and departmental decision-making were related to IAT score such that a more biased IAT score was marginally associated with greater self-reported stress and significantly associated with the perception that men were more responsible for departmental decision-making.

Table 1. Regression analysis for women faculty $(n=44)$ with IAT score predicted by departmental decision-making, imposter phenomenon, stress, and stereotype endorsement.

\begin{tabular}{llllll}
\hline & $B$ & $S E$ & $B$ & $t$ & $p$ \\
\hline Stereotype endorsement & .06 & .11 & .14 & .54 & .60 \\
Imposter phenomenon & -.13 & .21 & -.15 & -.63 & .54 \\
Stress & .01 & .01 & .46 & 1.95 & .07 \\
Departmental decision-making & .01 & .01 & .48 & 2.09 & .05 \\
\end{tabular}

Note. $R^{2}=.321$ 
To examine the relationships between engagement and variables that reflected competence and autonomy in female faculty, a regression analysis was performed predicting engagement as assessed by the UWES (Schaufeli et al., 2006) from departmental decisionmaking, imposter phenomenon, stress, and stereotype endorsement. As demonstrated in Table 2, UWES scores were significantly predicted by imposter phenomenon and departmental decisionmaking.

Table 2. Regression analysis for women faculty $(n=51)$ with engagement predicted by departmental decision-making, imposter phenomenon, stress, and stereotype endorsement.

\begin{tabular}{llllll}
\hline & $B$ & $S E$ & $B$ & $t$ & $p$ \\
\hline Stereotype endorsement & .12 & .10 & .18 & 1.15 & .26 \\
Imposter phenomenon & -.94 & .22 & -.65 & -4.34 & $<.01$ \\
Stress & .00 & .01 & .11 & .68 & .50 \\
Departmental decision-making & .02 & .01 & .46 & 3.09 & .01 \\
\hline
\end{tabular}

Note. $R^{2}=.558$

We also examined protective factors that could potentially mitigate negative psychological effects by increasing feelings of relatedness and belonging in women faculty. Specifically, we tested whether having an advocate or belonging to a women's organization would be related to implicit bias, engagement, perceptions departmental decision-making processes, stereotype endorsement, stress, and imposter phenomenon. As demonstrated in Table 3, results of independent samples t-tests indicated that, compared to participants who were not part of a women's organization $(n=32)$, those who were $(n=19)$ felt that men had marginally 
less decision-making power in their departments, $t(51)=-1.79, p=.09$, and had lower feelings of imposter phenomenon, $t(51)=2.01, p=.05$. Moreover, women who did have an advocate $(n=$ 37; 4 women advocates, 33 men advocates) reported marginally more engagement, $t(51)=1.94$, $p=.06$, and had lower feelings of imposter phenomenon, $t(51)=-2.53, p=.018$ compared to women without an advocate $(n=12)$. No other analyses yielded significant effects.

Table 3. Participation in a women's professional organization and having an advocate on implicit bias, engagement, departmental decision-making, imposter phenomenon, stress, and stereotype endorsement.

\begin{tabular}{|c|c|c|c|c|}
\hline & \multicolumn{2}{|c|}{ Women's organization } & \multicolumn{2}{|c|}{ Advocate } \\
\hline & Yes $(n=22)$ & No $(n=32)$ & Yes $(n=40)$ & No $(n=12)$ \\
\hline Implicit bias & $0.33(.64)$ & $0.41(.58)$ & $0.46(.62)$ & $0.22(.50)$ \\
\hline Engagement & $6.14(.88)$ & $5.77(.94)$ & $6.03(.82)^{\mathrm{c}}$ & $5.24(1.06)^{\mathrm{c}}$ \\
\hline Stereotype endorsement & $2.30(1.38)$ & $2.78(1.54)$ & $2.62(1.50)$ & $2.67(1.52)$ \\
\hline Imposter phenomenon & $2.28(.42)^{\mathrm{b}}$ & $2.74(.68)^{\mathrm{b}}$ & $2.44(.47)^{\mathrm{d}}$ & $3.13(.88)^{\mathrm{d}}$ \\
\hline Stress & $57.75(17.74)$ & $62.56(24.90)$ & $58.20(22.47)$ & $70.67(22.64)$ \\
\hline $\begin{array}{l}\text { Departmental decision- } \\
\text { making }\end{array}$ & $48.57(15.19)^{\mathrm{a}}$ & $39.38(17.03)^{\mathrm{a}}$ & $44.95(15.98)$ & $36.00(18.91)$ \\
\hline
\end{tabular}

Notes. Numbers reported are means. Numbers in parentheses represent standard deviations. Means with the same letter are significantly different from one another.

\section{Discussion}

The current study suggests that women STEM faculty at a R2 university face barriers to job engagement and professional success. Specifically, the women faculty in natural science 
departments work with men who hold implicit gender biases toward women in STEM. This finding is consistent with previous work demonstrating that sexist attitudes often occur in fields that are traditionally male-dominated (Hesson-McInnis \& Fitzgerald, 1997; Settles et al., 2006). In addition, women faculty in natural science departments in the current study felt marginally less engaged than women in social science departments, whereas there was no difference for men. Together, these findings suggest that, although advances in the representation of women STEM faculty have been made (e.g., NRC, 2009), women faculty in the natural sciences still have challenges to overcome.

Consistent with Self-Determination Theory, we hypothesized that implicit bias and engagement would be associated with women's perceptions of their own abilities (competency), the amount of control they have in departmental decision-making processes (autonomy), and the degree to which they feel that they belong (relatedness; Deci \& Ryan, 1985; Ryan \& Deci, 2000). The results of the current study revealed that feelings of autonomy (i.e., a voice in departmental decision-making) were associated with implicit bias and engagement. In addition, implicit bias was associated with self-reported stress while imposter phenomenon was associated with engagement. We also found that participation in a women's organization and having an advocate, both of which increase feelings of belonging and relatedness, served to ameliorate some of the barriers that STEM women faculty perceive. Thus, the results of this study partially supported our hypotheses in that they suggest that implicit bias is associated with factors related to autonomy, whereas engagement was associated with feelings of both competence and autonomy.

It is impossible from the current study to determine the direction of the relationship between the outcome and predictor variables; however, previous research provides some insight. 
With respect to implicit gender bias, previous work shows that greater endorsement of implicit stereotypes in science leads women faculty in STEM to experience higher levels of anxiety (e.g., LePine, Podsakoff, \& LePine, 2005; Rodell \& Judge, 2009). Implicit bias has also been shown to play a role in decisions about leadership. For example, in a study examining political voting behavior, Mo (2015) found that individuals who had greater implicit bias against women leaders were more likely to vote for a male candidate over an equally qualified female candidate. A similar process could explain the underrepresentation of women faculty in academic leadership roles. The scarcity of women leaders in STEM may further perpetuate perceptions that there is a lack of equity in decision-making (Morahan, Gleason, Richman, Dannels, \& McDade, 2010). Perceptions of departmental decision-making were also related to the degree to which women faculty in STEM felt engaged with their job. These results are consistent with previous research demonstrating that the most important predictor of STEM women faculty's engagement with their jobs is feeling valued and respected in one's department (Britton, Baird, Dyer, Middendorf, Montelone, \& Smith, 2012; Settles et al., 2006). In addition, consistent with previous work (e.g., Li et al., 2014), engagement was related to self-reported imposter phenomenon. Women who experience imposter phenomenon often report higher levels of stress (e.g., Chae et al., 1995; Clance \& Imes, 1978; Topping \& Kimmel, 1985), which can lead to decreased productivity and a greater intention to leave academia (Barnes et al., 1998).

However, despite these barriers to engagement, the current study suggests that having support and advocacy from an individual or a group may protect women faculty from some of the negative effects associated with gender bias. That is, having an advocate was associated with lower feelings of imposter phenomenon and marginally greater feelings of engagement. Belonging to a women's organization was associated with feeling less imposter phenomenon and 
marginally less sexist departmental decision-making than those not in an organization. There are a number of reasons for these findings. First, support and advocacy from an individual or a group can reduce feelings of isolation (Kemelgor \& Etzkowitz, 2001) and create a sense of belonging and relatedness (Good et al., 2012), which are associated with job satisfaction, performance, and persistence (Feldman et al., 2010). Second, support and advocacy from an individual or a group can provide women with networks that they typically have less access to than men (Milem et al., 2001) and help them identify and pursue opportunities for career advancement (Baltodano, Carlson, Jackson, \& Mitchell, 2012) and professional collaboration (Kemelgor \& Etzkowitz, 2001). Some organizations such as the European Commission for Women and Science are recognizing the benefits of professional networks for women STEM faculty, and are establishing conferences and networking organizations to facilitate these relationships (Husu, 2005).

In the current study, only four of the 37 advocates were women. Future research should examine whether the gender of the advocate differentially affects outcomes for women faculty. There is evidence from industry that women mentors and advocates may be more effective for women protégés as they can serve as effective role models (DeCastro, Sambuco, Ubel, Stewart, \& Jagsi, 2013); however, other research has shown that male mentors are associated with better career development (Sosik \& Godshalk, 2000). It has also been shown that in male-dominated work environments, female professionals who are mentored by senior men have the highest return on compensation and career progress satisfaction (Ramaswami, Dreher, Bretz, \& Wiethoff, 2010). Perhaps having a powerful male mentor or advocate may increase women's visibility and signal their worthiness within a male-dominated organization (Ramaswami et al., 2010). 
Although the findings regarding advocates and professional organizations suggests that they may be protective factors, it is important to remember that because this study was correlational, the direction of the relationship between these variables is unknown. For example, it is also possible that women who feel less like an imposter are more likely to seek out an advocate or join a women's organization. Future experimental research that assesses the effect of advocates and networking programs on women's outcomes in academia will provide insight into the directionality of these relationships. In addition, future research could test whether having an advocate moderates the relationship between implicit bias and psychological variables including imposter phenomenon and stress and then in turn whether these variables are related to engagement. Testing these models was not possible with the current sample size.

Although this research provides important information about the relationship between various barriers and protective factors that may be associated with women STEM faculty's experiences of implicit bias and engagement, the current project has some limitations. First, this study included a small sample which may have reduced its power to detect relationships between variables of interest and differences between natural and social science faculty. In addition, this study was conducted at a mid-size liberal arts university, which may have reduced the generalizability of the results. Despite these apparent limitations, it is worth noting that the findings reported herein replicate and extend previous research, which has primarily been conducted at large research-focused universities. Because this sample was taken from a university that places similar emphases on research and teaching, one might hypothesize that women at this institution would experience more engagement and less negative psychological outcomes than those at larger research-oriented research institutes. However, the findings of this study suggest that even at a smaller liberal arts-focused university that values both research and 
teaching, women in natural science departments still experience gender bias and less engagement than men, and these feelings are associated with anxiety, imposter phenomenon and feeling that they do not play a role in department decision-making. Future work should assess other universities that have different campus climates, are located in different regions, and have a different student and faculty composition.

Furthermore, although we were unable to examine the role of race in the current study due to the small number of faculty of color in our sample, future research should take into consideration intersecting identities such as race and gender when assessing faculty experiences in higher education (e.g., Pifer, 2011). For women faculty of color in STEM, being a member of two marginalized groups can lead to additional challenges such as experiencing implicit and explicit bias related to both race and gender (e.g., Borum \& Walker, 2012; Espinosa, 2008). Working in a racially-biased climate, as with working in a gender-biased climate, can affect faculty members' perceptions of the role they have in decision-making in the department. This negative perception of department climate, as demonstrated in the current study and in previous work with faculty of color, is negatively associated with engagement (Jayakumar, Howard, Allen, \& Han, 2009; Turner, Gonzalez, \& Wood, 2008), which is a predictor of intention to leave academia (Barnes et al., 1998). In the current study, engagement was also negatively associated with feelings of imposter phenomenon. Women faculty of color experience higher rates of imposter phenomenon compared to their White women colleagues (Alexander, 1995; Benjamin, 1997); thus, finding ways to reduce feelings of imposter phenomenon and thus increase engagement in women faculty of color is an important future research area. Experiencing these additional challenges may help explain why Black women faculty, compared to other 
intersectional faculty groups, are the most stressed, least satisfied, and most overworked (Alexander, 1995; Benjamin, 1997).

One way to potentially ameliorate some of these challenges for women faculty of color is having a network of mentors to help navigate the racial and gender challenges of academia (Sorcinelli \& Yun, 2007). Conferences focusing on professional development geared towards the unique experiences of faculty of color (e.g., networking, choosing mentors, service) can also be critical (Dancy \& Jean-Marie, 2014). Future work should examine if advocates and professional organizations can serve as protective factors for women faculty of color as they did for the (predominantly White) women in our study.

An additional direction of future research is to examine the role of faculty rank in understanding the experiences of women STEM faculty. Although we were unable to separate our small sample into groups based on academic rank, it is likely that women faculty in pretenure and post-tenure positions experience academia differently. Indeed, previous research has suggested that, in general, faculty at higher ranks experience greater engagement and less imposter phenomenon than pre-tenure faculty (Bender \& Heywood, 2006; Bozeman \& Gaughan, 2011; Oshagbemi, 1997). Thus, one might expect that tenured women STEM faculty in the current study would be more engaged at work than their untenured peers. It is unclear whether there would be an interaction between gender and rank with regards to job engagement as some studies find that women faculty in higher ranks report more engagement with their career than their male counterparts (Okpara, Squillace, \& Erandu, 2005; Oshagbemi, 1997) while other research shows no such interaction (Bilimoria et al., 2006; Bozeman \& Gaughan, 2011); future work should continue to investigate this question. Regardless of this relationship, because pretenure women faculty are more likely to leave their institution and to leave academia than post- 
tenure women $(\mathrm{Xu}, 2008)$, implementing advocacy programs and professional women's organizations for junior faculty such as the ones examined in the current study are imperative (Chang et al., 2016; Pollart et al., 2015).

The current work extends our understanding of some of the barriers that women faculty in STEM face and the protective factors that might improve outcomes. STEM women face challenges to success in academia as a function of their own biases as well as those of their male colleagues. The findings of the current study provide some insight into ways that institutions can better support women STEM faculty. First, universities can use evidence-based diversity training to reduce implicit biases toward women STEM faculty. Research has shown that short interventions such as videos or training sessions can reduce implicit bias in STEM faculty through increasing awareness of bias, reducing sexism, and improving bias identification (Hennes et al., 2018; Jackson, Hillard, \& Schneider, 2014; Moss-Racusin, Pietri, Hennes, Dovidio, Brescoll, \& Roussos, \& Handelsman, 2018). These training programs provide faculty with data on the representation of women in STEM, the effects of implicit bias on hiring and retention, and workplace climate; they also provide specific, practical recommendations for reducing bias (Jackson et al., 2014). Second, increasing the number of women STEM faculty can be an effective tool to increase engagement and reduce feelings of imposter phenomenon. Consistent with previous research, the current study showed that women faculty were less satisfied than their male counterparts only in natural science departments, where women made up a small minority of the faculty. Indeed, increasing the number of women STEM faculty has been shown to increase women faculty's perception that the department values women (Hillard, Schneider, Jackson, \& LaHuis, 2014). The National Science Foundation has put forth specific recommendations for improving recruitment processes to increase the hiring of women (e.g., 
training search committees on biases, targeted recruitment) as well as procedures for promotion and retention (e.g., information sessions on tenure) (see Bilimoria, Joy, \& Liang, 2008). Third, our research suggests that setting up and supporting advocacy programs and professional women's organizations can mitigate some of the negative psychological effects that STEM women faculty experience. These changes, in addition to policies that remove challenges that are unique to female faculty (e.g., maternity leave policies with accompanying tenure clock adjustments), may promote gender equity within STEM. 


\section{References}

Alexander, M. W. (1995). Black women in academia. In B. Guy-Sheftall (Ed.), Words of fire: An anthology of African-American feminist thought. (Rev. ed.) (pp. 454-460). New York: The New Press.

August, L., \& Waltman, J. (2004). Culture, climate, and contribution: Career satisfaction among female faculty. Research in Higher Education, 45(2), 177-192. doi:10.1023/B:RIHE.0000015694.14358.ed.

Bagilhole, B., \& White, K. (Eds.). (2013). Generation and Gender in Academia. London: Palgrave Macmillan.

Baltodano, J. C., Carlson, S., Jackson, L. W., \& Mitchell, W. (2012). Networking to leadership in higher education: National and state-based programs and networks for developing women. Advances in Developing Human Resources, 14(1), 62-78.

Barnes, L. L., Agago, M. O., \& Coombs, W. T. (1998). Effects of job-related stress on faculty intention to leave academia. Research in Higher Education, 39(4), 457-469.

Bender, K. A., \& Heywood, J. S. (2006). Job satisfaction of the highly educated: The role of gender, academic tenure, and earnings. Scottish Journal of Political Economy, 53(2), 253-279.

Benjamin, L. (1997). Black women in the academy: An overview. In L. Benjamin (Ed.), Black women in the academy: Promises and perils (pp. 1-7). Gainesville, FL: University Press of Florida.

Bezuidenhout, A., \& Cilliers, F. V. (2010). Burnout, work engagement and sense of coherence in female academics in higher-education institutions in South Africa. SA Journal of Industrial Psychology, 36(1), 1-10. 
Bilimoria, D., Joy, S., \& Liang, X. (2008). Breaking barriers and creating inclusiveness: Lessons of organizational transformation to advance women faculty in academic science and engineering. Human Resource Management: Published in Cooperation with the School of Business Administration, The University of Michigan and in alliance with the Society of Human Resources Management, 47(3), 423-441.

Bilimoria, D., Perry, S. R., Liang, X., Stoller, E. P., Higgins, P., \& Taylor, C. (2006). How do female and male faculty members construct job satisfaction? The roles of perceived institutional leadership and mentoring and their mediating processes. The Journal of Technology Transfer, 31(3), 355-365.

Blair, I. (2001). Implicit stereotypes and prejudice. In G. Moskowitz (Ed.), Cognitive social psychology: On the tenure and future of social cognition (pp. 359-374). Mahwah, NJ: Erlbaum.

Blanton, H., Christie, C., \& Dye, M. (2002). Social identity versus reference frame comparisons: The moderating role of stereotype endorsement. Journal of Experimental Social Psychology, 38(3), 253-267.

Borum, V., \& Walker, E. (2012). What makes the difference? Black women's undergraduate and graduate experiences in mathematics. Journal of Negro Education, 81(4), 366-378.

Bozeman, B., \& Gaughan, M. (2011). Job satisfaction among university faculty: Individual, work, and institutional determinants. The Journal of Higher Education, 82(2), 154-186.

Britton, D. M., Baird, C. L., Dyer, R. A., Middendorf, J., Montelone, B. A., \& Smith, C. (2012). Surveying the campus climate for faculty: A comparison of the assessments of STEM and non-STEM faculty. International Journal of Gender, Science and Technology, 4(1), $102-122$. 
Callister, R. R. (2006). The impact of gender and department climate on job satisfaction and intentions to quit for faculty in science and engineering fields. The Journal of Technology Transfer, 31(3), 367-375.

Ceci, S. J., \& Williams, W. M. (2011). Understanding current causes of women's underrepresentation in science. Proceedings of the National Academy of Sciences, 108(8), $3157-3162$.

Ceci, S. J., \& Williams, W. M. (2015). Women have substantial advantage in STEM faculty hiring, except when competing against more-accomplished men. Frontiers in Psychology, 6. doi: $10.3389 /$ fpsyg.2015.01532

Ceci, S. J., Williams, W. M., \& Barnett, S. M. (2009). Women's underrepresentation in science: Sociocultural and biological considerations. Psychological Bulletin, 135(2), 218-261.

Chae, J. H., Piedmont, R. L., Estadt, B. K., \& Wicks, R. J. (1995). Personological evaluation of Clance's Imposter Phenomenon Scale in a Korean sample. Journal of Personality Assessment, 65(3), 468-485.

Chang, S., Morahan, P. S., Magrane, D., Helitzer, D., Lee, H. Y., Newbill, S., ... \& Cardinali, G. (2016). Retaining faculty in academic medicine: The impact of career development programs for women. Journal of Women's Health, 25(7), 687-696.

Cheryan, S., Plaut, V. C., Davies, P. G., \& Steele, C. M. (2009). Ambient belonging: How stereotypical cues impact gender participation in computer science. Journal of Personality and Social Psychology, 97(6), 1045-1060.

Chesler, N. C., \& Chesler, M. A. (2002). Gender-informed mentoring strategies for women engineering scholars: On establishing a caring community. Journal of Engineering Education, 91(1), 49-55. 
Clance, P. R. (1985). The impostor phenomenon: Overcoming the fear that haunts your success. Atlanta, GA: Peachtree Publishers, Limited.

Clance, P. R., \& Imes, S. A. (1978). The imposter phenomenon in high achieving women: Dynamics and therapeutic intervention. Psychotherapy: Theory, Research and Practice, 15(3), 241-247.

Colquitt, J. A., Conlon, D. E., Wesson, M. J., Porter, C. O., \& Ng, K. Y. (2001). Justice at the millennium: A meta-analytic review of 25 years of organizational justice research. Journal of Applied Psychology, 86(3), 425-445.

Dancy, T. E., \& Jean-Marie, G. (2014) Faculty of color in higher education: Exploring the intersections of identity, impostorship, and internalized racism, Mentoring \& Tutoring: Partnership in Learning, 22(4), 354-372.

DeCastro, R., Sambuco, D., Ubel, P. A., Stewart, A., \& Jagsi, R. (2013). Mentor networks in academic medicine: Moving beyond a dyadic conception of mentoring for junior faculty researchers. Academic medicine: Journal of the Association of American Medical Colleges, 88(4), 488-496.

Deci, E. L., \& Ryan, R. M. (1985). Intrinsic motivation and self-determination in human behavior. New York, NY: Plenum Press.

Deci, E. L., \& Vansteenkiste, M. (2004). Self-determination theory and basic need satisfaction: Understanding human development in positive psychology. Ricerche di Psicologia. $27(1), 23-40$.

Denton, M., \& Zeytinoğlu, I. U. (1993). Perceived participation in decision-making in a university setting: The impact of gender. ILR Review, 46(2), 320-331. 
Diekman, A. B., Brown, E. R., Johnston, A. M., \& Clark, E. K. (2010). Seeking congruity between goals and roles: A new look at why women opt out of science, technology, engineering, and mathematics careers. Psychological Science, 21(8), 1051-1057.

Dovidio, J. F., \& Gaertner, S. L. (2004). On the nature of contemporary prejudice: The causes, consequences, and challenges of aversive racism. In J. Eberhardt \& S. T. Fiske (Eds.), Confronting racism: The problem and the response (pp. 3-32). Thousand Oaks, CA: SAGE Publishers.

Dovidio, J. F., Kawakami, K., \& Gaertner, S. L. (2002). Implicit and explicit prejudice and interracial interaction. Journal of Personality and Social Psychology, 82(1), 62-68.

Espinosa, L. L. (2008). The academic self-concept of African American and Latina(o) men and women in STEM majors. Journal of Women and Minorities in Science and Engineering, 14(2), 177-203.

Fazio, R. H., Jackson, J. R., Dunton, B. C., \& Williams, C. J. (1995). Variability in automatic activation as an unobtrusive measure of racial attitudes: A bona fide pipeline? Journal of Personality and Social Psychology, 69(6), 1013-1037.

Feldman, M. D., Arean, P. A., Marshall, S. J., Lovett, M., \& O’Sullivan, P. (2010). Does mentoring matter: Results from a survey of faculty mentees at a large health sciences university. Medical Education Online, 15(1), 5063, DOI: 10.3402/meo.v15i0.5063

Fine, M., \& Weis, L. (2003). Silenced voices and extraordinary conversations: Re-imagining schools. New York, NY: Teachers College Press

Fried-Buchalter, S. (1997). Fear of success, fear of failure, and the imposter phenomenon among male and female marketing managers. Sex Roles, 37(11), 847-859. 
Gander, J. P. (1999). Faculty gender effects on academic research and teaching. Research in Higher Education, 40(2), 171-184.

Glazer-Raymo, J. (1999). Shattering the myths: Women in academe. Baltimore, MD: Johns Hopkins University Press.

Good, C., Rattan, A., \& Dweck, C. S. (2012). Why do women opt out? Sense of belonging and women's representation in mathematics. Journal of Personality and Social Psychology, 102(4), 700-717.

Greenwald, A. G., Nosek, B. A., \& Banaji, M. R. (2003). Understanding and using the implicit association test: I. An improved scoring algorithm. Journal of Personality and Social Psychology, 85(2), 197-216.

Hagedorn, L. S. (2000). Conceptualizing faculty job satisfaction: Components, theories, and outcomes. New Directions for Institutional Research, 105, 5-20.

Harter, J. K., Schmidt, F. L., \& Hayes, T. L. (2002). Business-unit-level relationship between employee satisfaction, employee engagement, and business outcomes: A meta-analysis. Journal of Applied Psychology, 87(2), 268.

Heilman, M. E. (2001). Description and prescriptions: How gender stereotypes prevent women's ascent up the organizational ladder. Journal of Social Issues, 57, 657-674.

Hennes, E. P., Pietri, E. S., Moss-Racusin, C. A., Mason, K. A., Dovidio, J. F., Brescoll, V. L., ... \& Handelsman, J. (2018). Increasing the perceived malleability of gender bias using a modified Video Intervention for Diversity in STEM (VIDS). Group Processes \& Intergroup Relations, 21(5), 788-809.

Hesson-McInnis, M. S., \& Fitzgerald, L. F. (1997). Sexual harassment: A preliminary test of an integrative model. Journal of Applied Social Psychology, 27 (10), 877-901. 
Hillard, A. L., Schneider, T. R., Jackson, S. M., \& LaHuis, D. (2014). Critical mass or incremental change? The effects of faculty gender composition in STEM. In Gender Transformation in the Academy (pp. 355-374). Emerald Group Publishing Limited.

Holleran, S. E., Whitehead, J., Schmader, T., \& Mehl, M. R. (2011). Talking shop and shooting the breeze: A study of workplace conversation and job disengagement among STEM faculty. Social Psychological and Personality Science, 2(1), 65-71.

Hopkins, N., Bailyn, L., Gibson, L., \& Hammonds, E. (2002). The Status of Women Faculty at MIT: An Overview of Reports from the Schools of Architecture and Planning; Engineering; Humanities, Arts and Social Sciences; and the Sloan School of Management. Available at: www.MIT.edu/ faculty/reports/overview.html.

House of Commons Science and Technology Committee (2014). Women in Scientific Careers (London: House of Commons). Retrieved from https://publications.parliament.uk/pa/cm201314/cmselect/cmsctech/701/70102.htm.

Howe-Walsh, L., \& Turnbull, S. (2016). Barriers to women leaders in academia: tales from science and technology. Studies in Higher Education, 41(3), 415-428.

Hurtado, S., Eagan, M. K., Pryor, J. H., Whang, H., \& Tran, S. (2012). Undergraduate teaching faculty: The 2010-2011 HERI Faculty Survey. Los Angeles: Higher Education Research Institute, UCLA.

Husu, L. (2005). Towards gender equality in academia: problems, policies and practices. In International Conference "Creating Cultures of Success for Women Engineers” Conference Proceedings (pp. 13-33).

Jack, D. C. (1991). Silencing the self: Women and depression. Cambridge, MA: Harvard University Press. 
Jackson, S. M., Hillard, A. L., \& Schneider, T. R. (2014). Using implicit bias training to improve attitudes toward women in STEM. Social Psychology of Education, 17(3), 419-438.

Jayakumar, U., Howard, T. C., Allen, W. R., \& Han, J. C. (2009). Racial privilege in the professoriate: An exploration of campus climate, retention, and satisfaction. Journal of Higher Education, 80(5): 538-63.

Kemelgor, C., \& Etzkowitz, H. (2001). Overcoming isolation: Women's dilemmas in American academic science. Minerva, 39(2), 153-174.

Kiefer, A. K., \& Sekaquaptewa, D. (2007). Implicit stereotypes, gender identification, and mathrelated outcomes: A prospective study of female college students. Psychological Science, $18(1), 13-18$.

King, J. E., \& Cooley, E. L. (1995). Achievement orientation and the impostor phenomenon among college students. Contemporary Educational Psychology, 20(3), 304-312.

Kumar, S., \& Jagacinski, C. M. (2006). Imposters have goals too: The imposter phenomenon and its relationship to achievement goal theory. Personality and Individual Differences, 40(1), 147-157.

Legassie, J., Zibrowksi, E. M., \& Goldszmidt, M. A. (2008). Measuring resident well-being: Impostorism and burnout syndrome in residency. Journal of General Internal Medicine, 23(7): 1090-1094.

Lent, R. W., Sheu, H. B., Miller, M. J., Cusick, M. E., Penn, L. T., \& Truong, N. N. (2018). Predictors of science, technology, engineering, and mathematics choice options: A metaanalytic path analysis of the social-cognitive choice model by gender and race/ethnicity. Journal of Counseling Psychology, 65(1), 17. 
LePine, J. A., Podsakoff, N. P., \& LePine, M. A. (2005). A meta-analytic test of the challenge stressor-hindrance stressor framework: An explanation for inconsistent relationships. Academy of Management Journal, 48(5), 725-741.

Li, A., Early, S. F., Mahrer, N. E., Klaristenfeld, J. L., \& Gold, J. I. (2014). Group cohesion and organizational commitment: Protective factors for nurse residents' job satisfaction, compassion fatigue, compassion satisfaction, and burnout. Journal of Professional Nursing, 30(1), 89-99.

Liang, X. F., \& Bilimoria, D. (2007). The representation and experience of women faculty in STEM fields. In R. Burke \& M. Mattis (Eds.), Women and minorities in science, technology, engineering and mathematics: Upping the numbers (pp. 317-333). Northampton, MA: Edward Elgar Publishing.

Macey, W. H., \& Schneider, B. (2008). The meaning of employee engagement. Industrial and Organizational Psychology: Perspectives on Science and Practice, 1, 3-30.

Maranto, C. L., \& Griffin, A. E. (2011). The antecedents of a 'chilly climate' for women faculty in higher education. Human Relations, 64(2), 139-159.

Milem, J. F., Sherlin, J., \& Irwin, L. (2001). The importance of collegial networks to college and university faculty. In E. G. Creamer (Ed.), Working Equal: Academic Couples as Collaborators (pp. 146-166). New York, NY: Routledge Falmer.

Massachusetts Institute of Technology (1999). A study on the status of women faculty in science at MIT. Retrieved from Massachusetts Institute of Technology: http://web.mit.edu/fnl/women/women.pdf.

Mo, C. H. (2015). The consequences of explicit and implicit gender attitudes and candidate quality in the calculations of voters. Political Behavior, 37(2), 357-395. 
Morahan, P. S., Gleason, K. A., Richman, R. C., Dannels, S., \& McDade, S. A. (2010). Advancing women faculty to senior leadership in US academic health centers: Fifteen years of history in the making. NASPA Journal About Women in Higher Education, 3(1), $140-165$.

Moss-Racusin, C. A., Pietri, E. S., Hennes, E. P., Dovidio, J. F., Brescoll, V. L., Roussos, G., \& Handelsman, J. (2018). Reducing STEM gender bias with VIDS (video interventions for diversity in STEM). Journal of Experimental Psychology: Applied, 24(2), 236.

Mudrak, J., Zabrodska, K., Kveton, P., Jelinek, M., Blatny, M., Solcova, I., \& Machovcova, K. (2018). Occupational well-being among university faculty: A job demands-resources model. Research in Higher Education, 59(3), 325-348.

Murphy, M. C., Steele, C., \& Gross, J. (2007). Signaling threat: How situational cues affect women in math, science, and engineering settings. Psychological Science, 18(10), 879885.

National Research Council (NRC) (2009). Gender Differences at Critical Transitions in the Careers of Science, Engineering and Mathematics Faculty. Washington, DC: National Academy Press.

National Science Board (2012). Science and Engineering Indicators. Arlington, VA: National Science Foundation.

National Science Foundation (2004). Women, Minorities, and Persons with Disabilities: 2004 (NSF Document No. nsf04317).

Niemeier, D. A., \& Gonzalez, C. (2004). Breaking into the Guildmasters' Club: What we know about women science and engineering department chairs at AAU universities. NWSA Journal, 16 (1), 157-171. 
Nosek, B. A, Banaji, M. R., \& Greenwald, A. G. (2002). Math= male, me= female, therefore math $\neq$ me. Journal of Personality and Social Psychology, 83(1), 44-59.

Nosek, B. A, Smyth, F. L., Sriram, N., Lindner, N. M., Devos, T., Ayala, A., Bar-Anan, Y., et al. (2009). National differences in gender-science stereotypes predict national sex differences in science and math achievement. Proceedings of the National Academy of Sciences, 106(26), 10593-10597.

O'Dorchai, S., Meulders, D., Crippa, F., \& Margherita, A. (2009). She figures 2009-Statistics and indicators on gender equality in science. Luxembourg: Publications Office of the European Union.

Okpara, J. O., Squillace, M., \& Erondu, E. A. (2005). Gender differences and job satisfaction: a study of university teachers in the United States. Women in Management Review, 20(3), 177-190.

Oshagbemi, T. (1997). The influence of rank on the job satisfaction of organizational members. Journal of Managerial Psychology, 12(8), 511-519.

Park, S. M. (1996). Research, teaching, and service: Why shouldn't women's work count? The Journal of Higher Education, 67(1), 46-84.

Pifer, M. J. (2011). Intersectionality in context: A mixed-methods approach to researching the faculty experience. New Directions for Institutional Research, 2011(151), 27-44.

Preston A. (2004). Leaving science: Occupational exit from science careers. New York, NY: Russell Sage Foundation.

Pollart, S. M., Novielli, K. D., Brubaker, L., Fox, S., Dandar, V., Radosevich, D. M., \& Misfeldt, M. L. (2015). Time well spent: The association between time and effort allocation and intent to leave among clinical faculty. Academic Medicine, 90(3), 365-371. 
Ramaswami, A., Dreher, G. F., Bretz, R., \& Wiethoff, C. (2010). Gender, mentoring, and career success: The importance of organizational context. Personnel Psychology, 63(2), 385405.

Riegle-Crumb, C., \& Morton, K. (2017). Gendered expectations: Examining how peers shape female students' intent to pursue STEM fields. Frontiers in Psychology, 8, 329.

Rodell, J. B., \& Judge, T. A. (2009). Can "good" stressors spark "bad" behaviors? The mediating role of emotions in links of challenge and hindrance stressors with citizenship and counterproductive behaviors. Journal of Applied Psychology, 94(6), 1438-1451.

Rosser, S. V. (2004). The science glass ceiling: Academic women scientists and the struggle to succeed. New York, NY: Routledge.

Ryan, R. M., \& Deci, E. L. (2000). Self-determination theory and the facilitation of intrinsic motivation, social development, and well-being. American Psychologist, 55(1), 68-78.

Sagebiel, F. (2005). Gendered organisational cultures in engineering. Theoretical reflections on WomEng results and future research perspectives. Creating Cultures of Success for Women Engineers, 143.

Schaufeli, W. B., Bakker, A. B., \& Salanova, M. (2006). The measurement of work engagement with a short questionnaire: A cross-national study. Educational and Psychological Measurement, 66(4), 701-716.

Schmader, T., Johns, M., \& Barquissau, M. (2004). The costs of accepting gender differences: The role of stereotype endorsement in women's experience in the math domain. Sex Roles, 50(11), 835-850.

Schneider, B. (1975). Organizational climates: An essay. Personnel Psychology, 28(4), 447-479. 
Schneider, B., Ehrhart, M. G., \& Macey, W. H. (2013). Organizational climate and culture. Annual Review of Psychology, 64, 361-388.

Settles, I. H., Cortina, L. M., Malley, J., \& Stewart, A. J. (2006). The climate for women in academic science: The good, the bad, and the changeable. Psychology of Women Quarterly, 30, 47-58.

Settles, I. H., Cortina, L. M., Stewart, A. J., \& Malley, J. (2007). Voice matters: Buffering the impact of a negative climate for women in science. Psychology of Women Quarterly, 31(3), 270-281.

Shollen, S. L., Bland, C. J., Finstad, D. A., \& Taylor, A. L. (2009). Organizational climate and family life: How these factors affect the status of women faculty at one medical school. Academic Medicine, 84(1), 87-94.

Sonnert, G., \& Holton, G. (1996). Career patterns of women and men in the sciences. American Scientist, 84(1), 63-71.

Sorcinelli, M. D., \& Yun, J. (2007). From mentor to mentoring networks: Mentoring in the new academy. Change: The Magazine of Higher Learning, 39(6), 58-61.

Sosik, J. J., \& Godshalk, V. M. (2000). The role of gender in mentoring: Implications for diversified and homogenous mentoring relationships. Journal of Vocational Behavior, 57(1), 102-122.

Spelke, E. S. (2005). Sex differences in intrinsic aptitude for mathematics and science? A critical review. American Psychologist, 60(9), 950-558.

Stanley, C. A. (2006). Faculty of color: Teaching in predominantly white colleges and universities. Bolton, MA: Anker Publishing Company, Inc. 
Steele, C. M. (1997). A threat in the air: How stereotypes shape intellectual identity and performance. American Psychologist, 52(6), 613.

Stockard, J., Greene, J., Lewis, P., \& Richmond, G. (2010). Promoting mentoring among and for women in chemistry: The experiences of COACh. In K.K. Kankstis, B.L. Gurley, M. Rossi, \& L.L. Wright (Eds.), Mentoring strategies to facilitate the advancement of women faculty (pp. 153-163). American Chemical Society Symposium Series, 1057. Retrieved at http://pubs.acs.org/doi/abs/10.1021/bk-2010-1057.ch011.

Thompson, T., Davis, H., \& Davidson, J. (1998). Attributional and affective responses of impostors to academic success and failure outcomes. Personality and Individual Differences, 25(2), 381-396.

Topping, M. E., \& Kimmel, E. B. (1985). The imposter phenomenon: Feeling phony. Academic Psychology Bulletin. 7(2), 213-226.

Turner, C., Gonzalez, J. C., \& Wood. J. L. (2008). Faculty of color in academe: What 20 years of literature tells us. Journal of Diversity in Higher Education, 1(3): 139-68.

Van den Berg, B. A. M., Bakker, A. B., \& Ten Cate, T. J. (2013). Key factors in work engagement and job motivation of teaching faculty at a university medical centre. Perspectives on Medical Education, 2(5-6), 264-275.

White, K. (2015). Keeping Women in Science. Carlton Victoria: Melbourne University Publishing.

Xu, Y. J. (2008). Gender disparity in STEM disciplines: A study of faculty attrition and turnover intentions. Research in Higher Education, 49(7), 607-624. 